\title{
Intensification of Heat and Mass Transfer by the Interaction of Two Drops of Water of Different Sizes
}

\author{
V. V. Glezer ${ }^{1}$ and A. V. Zhuikover, a) \\ ${ }^{1}$ Institute of Thermophysics Siberian Branch, 630090 Novosibirsk, Russia. \\ ${ }^{2}$ Siberian Federal University, 660041 Krasnoyarsk, Russia. \\ a)Corresponding author: a.v.zhuikov@mail.ru
}

\begin{abstract}
An interaction of an incident drop on a sessile drop located on a hot wall was experimentally investigated. The behavior of convection with and without graphite particles was studied. Graphite particles lead to a decrease of mass transfer after droplet fall. The falling droplet caused a narrow temporal leap in speed into sessile drop.
\end{abstract}

\section{INTRODUCTION}

The process of dropping drops is observed both in nature (rain) and in various technologies related to cleaning and cooling surfaces, coating, extinguishing fires. Falling drops during rain cause erosion of soils, rocks, historical structures, monuments [1]. Drops and films of aqueous saline are used in desalination technologies of sea water [2, 3]. Spray cooling of surfaces of power equipment depends on the methods of intensification of convection. The intensification of convection is important for increasing the heat transfer coefficient and evaporation rate. When simulating the evaporation of a liquid droplet on a heated wall, it is necessary to take into account free convection both in the liquid and in the gas phase [4-10]. The wettability of the wall affects the rate of evaporation and mass transfer $[11,12]$. The evaporation of salt solutions with a high salt concentration in the solution is accompanied by the appearance of crystals or crystalline hydrates [13-19]. Evaporation droplets using surfactant are considered in [20]. The dissociation of gas hydrates during combustion is accompanied by the appearance of water droplets on the surface of hydrates [21, 22]. Heat transfer and evaporation of water droplets must be taken into account during the dissociation of gas hydrates [23-29]. Drops in the stream during spray cooling can merge or disintegrate when interacting with each other. When a drop falls on a heated wall, it is accompanied by its expansion and cooling of the wall. Drops falling on the surface of the liquid can merge with the liquid or bounce off of it. If the impact energy is high, then the dropping drop on the surface of the liquid can lead to the formation of a corona on the surface [1].

The aim of this work was an experimental study of the interaction of two drops of water when a cold drop falls on the surface of a hot drop.

\section{EXPERIMENTAL METHODS}

In Fig. 1. presents a diagram of the experimental setup. Ambient temperature was $20{ }^{\circ} \mathrm{C}$, humidity was $40 \%$, external atmospheric pressure was $1 \mathrm{~atm}$. In the experiments, an aluminum substrate with a diameter of $40 \mathrm{~mm}$ and a height of $6 \mathrm{~mm}$ was used. The wall temperature $T_{\mathrm{w}}=87^{\circ} \mathrm{C}$ of the copper (1) under the drop 1 was measured by thermocouples (2) located at a distance of $0.5 \mathrm{~mm}$ from the wall. The temperature was maintained constant by changing the power of the electric heater (3), from which the substrate was heated. Drop 1 was created on the heated substrate using dispenser (4). The initial drop volume 1 was $V_{01}=55 \mu \mathrm{l}$, diameter $D_{01}=10 \mathrm{~mm}$. The initial height drop1 $h_{01}=1.7-1.9 \mathrm{~mm}$. The initial volume of droplet $2 V_{02}=2.6 \mu 1$ and the initial diameter of $d_{02}=0.95 \mathrm{~mm}$. In the experiments the composition of drop 1 changed: 1) distillate, 2) water-graphite suspension. The mass concentration of graphite particles in water was $1 \%$. The particle size of graphite was 10-20 $\mu \mathrm{m}$. The creation of 
drop 1 using a dispenser excluded a drop decay. The height of droplet 2 fall was $4-5 \mathrm{~mm}$. The time $t=0 \mathrm{~s}$ (Fig. 2) corresponds to the time when drop 1 was placed on the hot wall. The time of droplet 2 fall corresponded to 9-10 s (Fig. 2).

The temperature of drop 2 corresponded to the ambient temperature $\left(20^{\circ} \mathrm{C}\right)$. Weber number of droplet $2 \mathrm{We}=$ $\left(\rho u_{2} d_{02}\right) / \sigma=1.2$, where $\rho$ is the liquid density, $u_{2}$ is the droplet 2 fall velocity before touching the upper surface of the sitting drop, and $\sigma$ is the surface tension of the fluid. When droplet 2 fell, it flowed down on the surface of drop 1. The value of the $W e$ number in the experiments was low; then the dropping of a droplet onto a droplet did not lead to the formation of a corona and the droplet did not decay. All experiments were performed three times and the geometric parameters of the droplets (heights and diameters) corresponded to the average values for three repeated experiments.

To obtain average velocities in the horizontal cross section of water droplets, a Quantel Ever Green 70 double solid-state Nd: YAG laser was used in the experiments. The characteristics of the laser knife in the experiments were: wavelength $-532 \mathrm{~nm}$, repetition frequency $-4 \mathrm{~Hz}$, pulse energy $-70 \mathrm{~mJ}$. Cylindrical lenses with an opening angle of 22. An imperX IGV-B2020M video camera (5) was used to record droplet images. The measuring scheme of the PIV method is shown in Fig. 1. ActualFlow software was used to process the data and construct the droplet temperature fields. The average velocity in the liquid was measured in the horizontal section of the drop 1 at the same distance from the wall equal to $1 \mathrm{~mm}$. Velocity was averaged over the entire measured horizontal section of the drop 1.

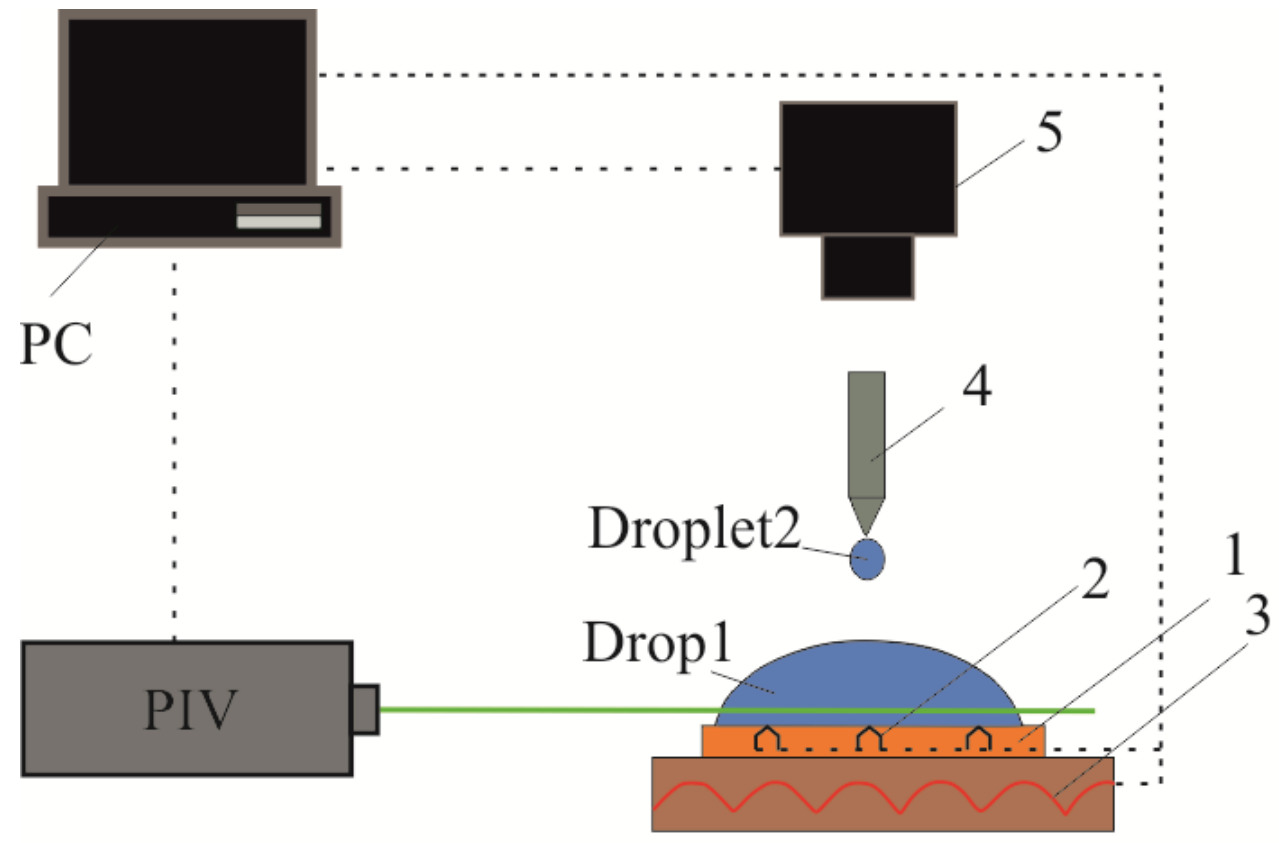

FIGURE 1.Experimental setup: 1 - heated horizontal substrate; 2 - thermocouples; 3 - heater power; 4 - dispenser; 5 - video camera.

\section{RESULTS AND DISCUSSION}

Fig. 2 shows the experimental data for the average velocity fields inside drop 1 obtained using the PIV method. After placing a cold drop 1 (the drop 1 temperature was $20^{\circ} \mathrm{C}$ ) on a heated substrate $\left(T_{\mathrm{w}}=87{ }^{\circ} \mathrm{C}\right.$ ) the strong convective flows arise inside the drop 1 which depend on the buoyancy force ( $R a$ number) and thermocapillary convection $\left(M a_{\mathrm{T}}\right) . R a=g \beta \Delta T\left(R_{01}\right)^{3} / v a ; M a_{\mathrm{T}}=\left(\Delta T h_{01} / \mu a\right) \cdot\left(d \sigma / d T_{\mathrm{S}}\right)$, where $\sigma$ is the surface tension of the liquid, $h_{01}$ is the drop height $\left(h_{01}=1.9 \mathrm{~mm}\right), \mu$ is the dynamic viscosity, $g$ is the gravity acceleration, $v$ is the kinematic viscosity of the water, $a$ is the thermal diffusivity, $\beta$ is the coefficient of thermal expansion. In the first seconds the velocity has a maximum value due to the maximum temperature gradient $\Delta T=T_{\mathrm{w}}-T_{\mathrm{s}}\left(T_{\mathrm{s}}\right.$ - temperature on the 
interface of the drop 1). After heating the liquid ( $t>6-10 \mathrm{~s})$ a further drop in the velocity is associated with a decrease in the drop height. When water evaporates the drop height decreases.

Fig. 3 shows the change in the average velocity for drop1 for water (points 1) and for water-graphite suspension (points 2). The time of droplet 2 fall corresponds to $9 \mathrm{~s}$. The use of water-graphite suspension led to a decrease in the average speed by 1.6 times compared with water at the initial drop time. For a droplet consisting of a water-graphite suspension, the droplet heating time is 3-4 s (for a water droplet is 5-7 s). Perhaps this is due to the suppression of $M a_{\mathrm{T}}$ convection due to the influence of graphite particles which reduced the surface tension gradient. After the droplet 2 fall an increase in the average velocity $u_{\text {aver }}$ by $6-8$ times was observed. At the same time for drop 1 consisting of a water-graphite suspension (points 2 ) the velocity increased by 3.0-3.5 times.

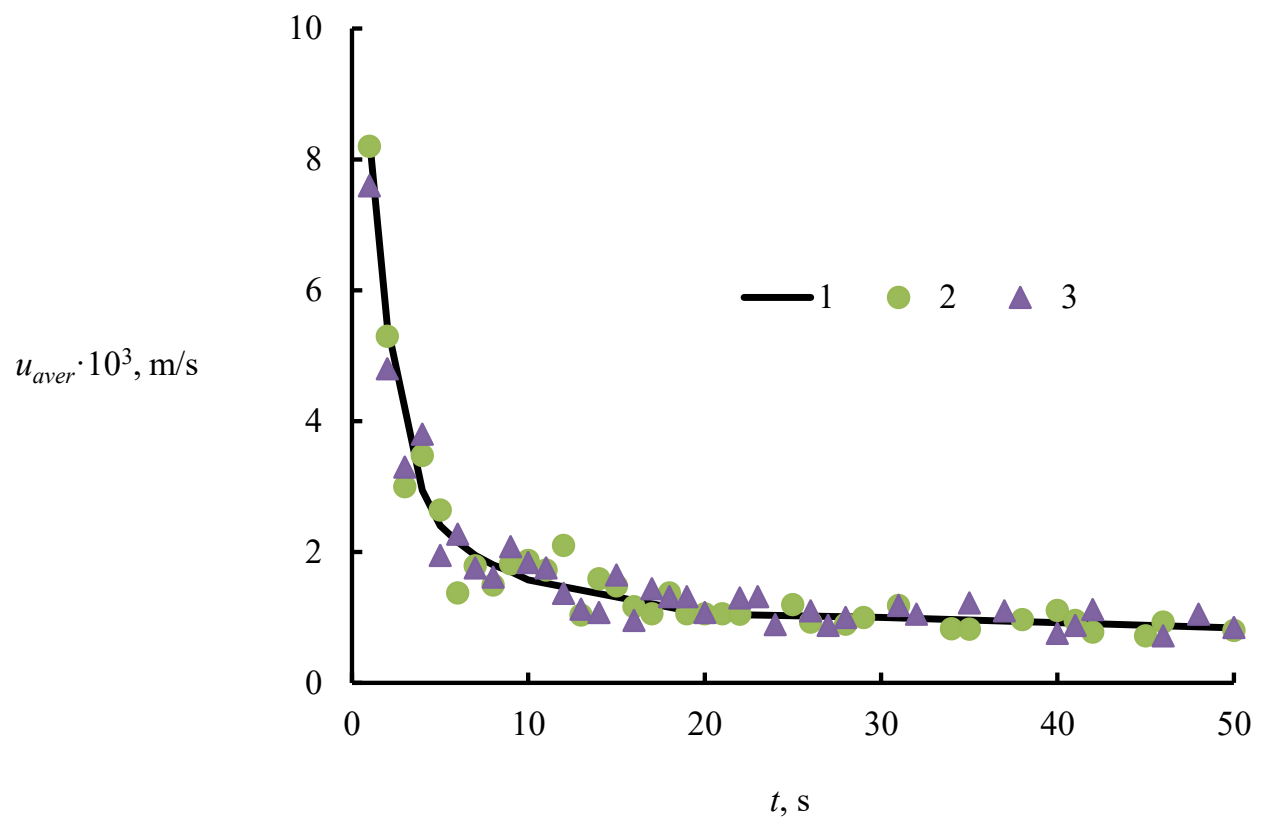

FIGURE2. Change in the average velocity $u_{\text {aver }}$ for drop 1 in time section obtained using the PIV method $\left(T_{\mathrm{w}}=87^{\circ} \mathrm{C}, h_{01}=1.9\right.$ $\mathrm{mm}$ ). 


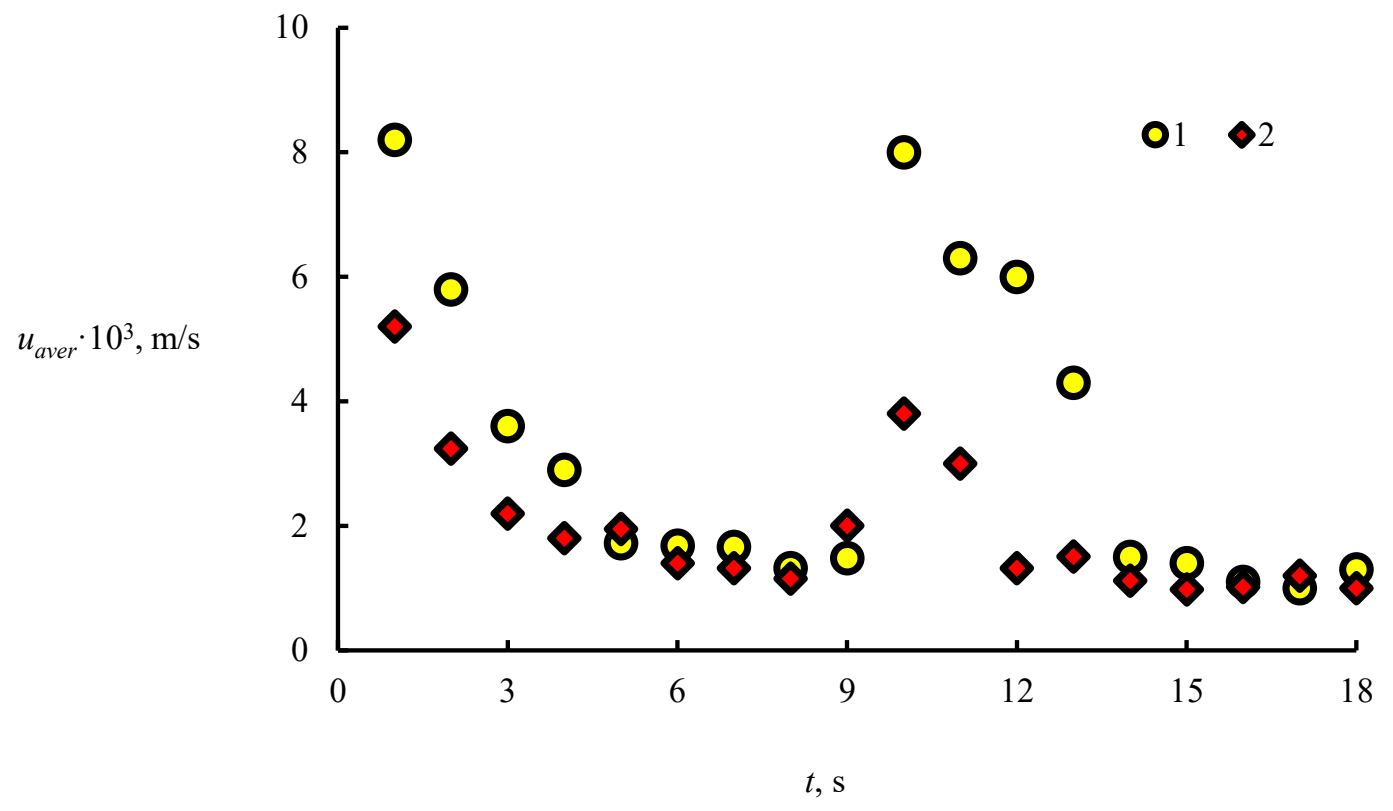

FIGURE3. Change in the average velocity $u_{\text {aver }}$ for drop 1 over the time interval obtained using the PIV $\operatorname{method}\left(T_{\mathrm{w}}=87^{\circ} \mathrm{C}\right.$, $\left.h_{01}=1.9 \mathrm{~mm}\right) 1$ - water; 2 - water-graphite suspension; when a Droplet 2 of water falls.

When droplet 2 fall (Fig. 4(b)) ( $t=10 \mathrm{~s}$ ) the direction of motion of the $M a_{\mathrm{T}}$ force will change, since the center of the surface of drop 1 will cool (the temperature of droplet 2 corresponds to ambient temperature). After 3 seconds has passed after droplet 2 fall the droplet 1 surface in the droplet center warms up ( $T_{\mathrm{s}}$ increases, $\sigma$ falls) and the motion direction of the $M a_{\mathrm{T}}$ force changes to the opposite one.

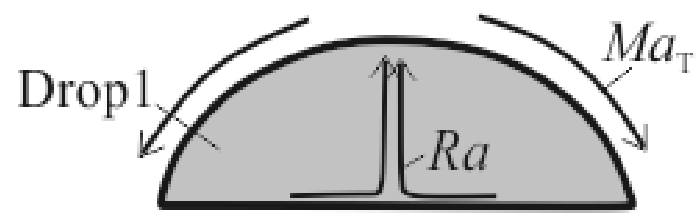

(a)

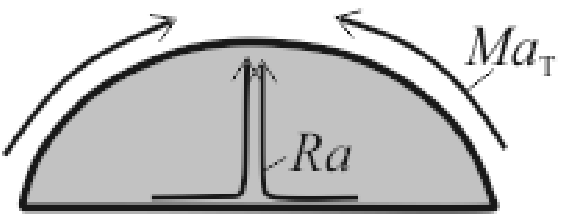

(b)

FIGURE4. Rotation direction of the water in drop 1 depending on the $M a \mathrm{~T}, M a_{\mathrm{C}}$, and $R a$ with time: a) until droplet 1 fall; b) after the droplet 1 fall (water, $t=10 \mathrm{~s}$ ).

Thus, when modeling a spray, it is necessary to take into account a change in the direction of surface forces.

\section{CONCLUSIONS}

The liquid velocity inside the sessile drop 1 decreases in the first $5-7 \mathrm{~s}$ due to heating of the liquid. This drop is due to a decrease in the Marangoni force. The behavior of convection with and without graphite particles was studied. Graphite particles lead to a decrease of mass transfer after droplet fall. The falling droplet caused a narrow temporal leap in speed into sessile drop. When modeling a spray cooling, it is necessary to take into account a change in the direction of Marangoni surface forces. The direction of the forces changes over a short time interval after the droplets fall on a liquid layer (film). 


\section{ACKNOWLEDGMENTS}

This work was carried out under state contract with IT SB RAS.

\section{REFERENCES}

1. M. Rein, Fluid Dynamics Res. 12, 61-93 (1993).

2. G. Liang and I. Mudawar, Int. J. Heat Mass Transf. 106, 103-126 (2017).

3. S. Shen, G. Liang, Y. Guo, R. Liu, and X. Mu, Water Treat. 51, 830-836 (2013).

4. S. Y. Misyura, Chem. Eng. Research Design 129, 306-313 (2018).

5. V. E. Nakoryakov and S.Y. Misyura, Doklady Physics 59, 441-445 (2014).

6. P. A. Strizhak, R. S. Volkov, S. Y. Misyura, S. I. Lezhnin, and V. S. Morozov, Int. J. Therm. Sci. 134, 421439 (2018).

7. R. S. Volkov, P. A. Strizhak, S. Y. Misyura, S. I. Lezhnin, and V. S. Morozov, Exp. Therm. Fluid Sci. 99, 59-70 (2018).

8. S. Y. Misyura, Int. J. Heat and Mass Transf. 116, 667-674 (2018).

9. V. E. Nakoryakov, S. Ya. Misyura, and S. L. Elistratov, J. Eng. Thermopsh. 22, 1-6 (2013).

10. V. E. Nakoryakov, S. Ya. Misyura, S. L. Elistratov, and R. A. Dekhtyar, J. Eng. Thermopsh. 23, 257-263 (2014).

11. G. V. Kuznetsov, D. V. Feoktistov, E. G. Orlova, K. Batishcheva, and S. S. Ilenok, Appl. Surf. Sci. 469, 974-982 (2019).

12. S. Y. Misyura, P. A. Strizhak, R. S. Volkov and V. S. Morozov, J. Molecular Liquids 294, 111670 (2019)

13. S. Y. Misyura, Cryst. Growth Des. 18, 1327-1338 (2018).

14. S. Y. Misyura, Appl. Therm. Eng. 139, 203-212 (2018).

15. V. E. Nakoryakov, S. L. Elistratov and S.Y. Misyura, J. Eng. Thermopsh. 20, 338-343 (2011).

16. G. V. Kuznetsov, D. V. Feoktistov, E. G. Orlova, S. Y. Misyura, V. S. Morozov, and A. G. Islamova, Int. J. Heat Mass Transf. 126, 161-168 (2018).

17. V. E. Nakoryakov, S. L. Elistratov, and S.Y. Misyura, J. Eng. Thermopsh. 20, 338-343 (2011).

18. S. Y. Misyura, Int. J. Therm. Sci. 124, 76-84 (2018).

19. S. Semenov, A. Trybala, H. Agogo, N. Kovalchuk, F. Ortega, R. G. Rubio, V. M. Starovand, and M. G. Velarde, Langmuir 29, 10028-10036 (2013).

20. V. E. Nakoryakov, S. Ya. Misyura, S. L. Elistratov, A. Yu. Manakov, and A. E. Shubnikov, J. Eng. Thermopsh. 22, 87-92 (2013).

21. S. Y. Misyura, Energy 103, 430-439 (2016).

22. S. Y. Misyura and I. G. Donskoy, Chem. Eng. Sci. 148, 65-77 (2016).

23. N. G. Musakaev, M. K. Khasanov, and S. L. Borodin, Int. J. Heat Mass Transf. 118, 455-461 (2018).

24. A. V. Meleshkin, M. V. Bartashevich, and V. V. Glezer, Appl. Surf. Sci. 493, 847-851 (2019).

25. V. Sh. Shagapov, Yu. A. Yumagulova, and N. G. Musakaev, J. App. Mech. Tech. Phys. 58, 189-199 (2017).

26. M. K. Khasanov, M. V. Stolpovsky, and I. K. Gimaltdinov, Int. J. Heat Mass Transf. 127, 21-28 (2018).

27. M. K. Khasanov, M. V. Stolpovsky, and I. K. Gimaltdinov, Int. J. Heat Mass Transf. 132, 529-538 (2019).

28. V. E. Nakoryakov, I. V. Mezentsev, A. V. Meleshkin, D. S. Elistratov, and A. Y. Manakov, J. Eng. Thermopsh. 24, 335-337 (2015). 